\title{
Vitamin D Status May Explain Some of the Racial Disparities in Rectal Cancer
}

\author{
William B. Grant, PhD \\ Sunlight, Nutrition, and Health Research Center, San Francisco
}

\section{TO THE EDITOR:}

The paper by Nitzkorski and colleagues determined that age, stage at diagnosis, and race were independent predictors of survival after diagnosis of rectal cancer. ${ }^{1}$ They suggested that factors other than socioeconomic status might explain why blacks had lower survival rates than whites.

Overlooked in the discussion was vitamin $\mathrm{D}$ status. Higher serum 25-hydroxyvitamin D [25(OH)D] levels at time of diagnosis of colorectal cancer were found associated with lower mortality rates. Those in the highest quartile of $25(\mathrm{OH}) \mathrm{D}$ [mean value, $40.0 \mathrm{ng} / \mathrm{ml}$ ) had an adjusted hazard ratio of 0.52 [95\% confidence interval (CI), $0.29-0.94]$ for overall mortality compared with those in the lowest quartile (mean value, $16.5 \mathrm{ng} / \mathrm{ml}$ ). ${ }^{2}$ Colon and rectal cancer mortality rates have similar geographical variations in the United States with respect to solar ultraviolet-B doses, an index of vitamin $\mathrm{D}$ production, and often are combined due to the lower numbers of rectal cancer cases. ${ }^{3}$

The role of vitamin D status in explaining black-white disparities in survival rates after diagnosis of cancer was reviewed recently. ${ }^{4}$ Eleven types of cancer have been found to have black-white disparities in survival rates after consideration of socioeconomic status, stage at diagnosis, and treatment. Elderly black Americans have serum 25(OH)D levels near $16-17 \mathrm{ng} / \mathrm{ml}$, whereas elderly white Americans have serum 25(OH)D levels near $25 \mathrm{ng} / \mathrm{ml} .^{5}$
Based on serum 25(OH)D level-colon cancer incidence rate relations, the difference is thought to be responsible for approximately a $25 \%$ difference in survival rates, which is within the range of $10-102 \%$ found by Nitzkorski et al. ${ }^{1}$.

Perhaps Nitzkorski and colleagues can add consideration of vitamin $\mathrm{D}$ in their future studies of rectal cancer outcome disparities.

CONFLICT OF INTEREST Dr. Grant received funding from Bio-Tech Pharmacal (Fayetteville, AR), the Sunlight Research Forum (Veldhoven), the UV Foundation (McLean, VA), the Vitamin D Council (San Luis Obispo, CA), and the Vitamin D Society (Canada).

\section{REFERENCES}

1. Nitzkorski JR, Willis AI, Nick D, Zhu F, Farma JM, Sigurdson ER. Association of race and socioeconomic status and outcomes of patients with rectal cancer. Ann Surg Oncol. 2013;20:1142-7.

2. $\mathrm{Ng} \mathrm{K}$, Meyerhardt JA, Wu K, Feskanich D, Hollis BW, Giovannucci EL, et al. Circulating 25-hydroxyvitamin D levels and survival in patients with colorectal cancer. J Clin Oncol. 2008;26:2984-91.

3. Grant WB, Garland CF. The association of solar ultraviolet B (UVB) with reducing risk of cancer: multifactorial ecologic analysis of geographic variation in age-adjusted cancer mortality rates. Anticancer Res. 2006;26:2687-99.

4. Grant WB, Peiris AN. Differences in vitamin D status may account for unexplained disparities in cancer survival rates between African and white Americans. Dermatoendocrinol. 2012;4:85-94.

5. Ginde AA, Liu MC, Camargo CA Jr. Demographic differences and trends of vitamin D insufficiency in the U.S. population, 1988-2004. Arch Intern Med. 2009;169:626-32. 